\title{
Proteção do "Software" pelo Direito do de Autor
}

\author{
Adriana Camargo Rodrigues Casella \\ Aluna de Pós-Graduação da FDUSP
}

RESUMO: I. A Informatizaçāo da Sociedade - a. O desenvolvimento da Informática e seu impacto na sociedade; b. A importância do software. II. O Software - a. O que é software; b. Partes componentes; c. Principais problemas. III. A Proteção Jurídica do Scftware - a. Etapas seguidas; b. Tratamento do tema no exterior; c. Tratamento do tema no Brasil. IV. O Software no Direito de Autor - a. Campo de atuaçăo do Direito do Autor; b. Requisitos para a proteçāo; c. Argumentos contrários; d. Argumentos favoráveis. V. Legislaçâo Especial - a. Base no Direito de Autor; b. Atençâo aos principais problemas.

RESUMÈ: I. L'informatisation de la societé - a. Le développement de l'informatique et sa répercussion dans la société; b. L’importance du logiciel - II. Le logiciel - a. La définition de logiciel; b. Les composants; $c$. Les principaux problèmes - III. La protection juridique du logiciel - a. Les étapes suivies; b. Le traitement du sujet à l'étranger; c. Le traitement du sujet au Brésil - IV. Le logiciel dans le cadre du droit d'auteur - a. Le domaine du droit d'auteur; b. Les conditions de protection; $c$. Les arguments contraires; $d$. Les arguments favorables - V. La législation spéciale-a. Le fondement sur le droit d'auteur; $b$. Les principales difficultés.

\section{UNITERMO}

INFORMATIZAÇÃO - processo de desenvolvimento fundado em técnicas informáticas;

SOFTWARE - programa de computador;

SOFTWARE DE BASE - refere-se ao modo de funcionamento dos computadores;

SOFTWARE APLICATIVO - permite aos computadores a obtenção de resultados específicos;

HARDWARE - conjunto de elementos mecânicos e eletrônicos de um computador.

\section{A INFORMATIZAÇĀO DA SOCIEDADE}

Contrariamente ao que muitos pensam, a informática nāo é a tecnologia do futuro; é a tecnologia do presente e que está alterando o panorama da socie- 
dade contemporânea. Hoje, já podemos falar numa terceira onda de desenvolvimento ${ }^{(1)}$, já podemos falar num processo de informatização da sociedade ${ }^{(2)}$.

\section{a. $\mathbf{O}$ desenvolvimento da informática e seu impacto na sociedade}

A partir da década de 70 , com a invenção dos microprocessadores, a informática disseminou-se por todos os campos da vida social. Desde as tarefas mais simples (como um mero jogo de diversão) até às mais complexas (planejamento de uma estratégia militar), o homem sujeita-se à utilização de meios informáticos. Este fato incontestável é propiciado pelo desenvolvimento das técnicas informáticas, o qual, por sua vez, conduz o uso da informática em campos cada vez mais abrangentes; por outro lado, concorrem para este fenômeno, a rapidez, a economia e a certeza destas técnicas.

Contudo, este processo não se desenrola pacificamente. Inúmeras questões têm aflorado em todos os campos da vida humana, dentre as quais, adquirem maior relevância, as seguintes: a privacidade do indivíduo, o transbordo de dados, a automação industrial e a proteção jurídica do software, entre outras. Esta última questão adquire especial importância, em razão do papel desempenhado pelo software neste processo de informatização.

\section{b. A importância do software neste processo}

O software surge como a grande chave que desencadeia esta terceira onda; atrás de toda a informatização há um computador, sem o qual aquela não seria possível.

O computador é uma máquina que concentra suas atividades básicas nos seguintes momentos: criação, processamento e armazenamento ${ }^{(3)}$. No momento da criação são elaborados os programas e os planos a serem aplicados no mo-

(1) Alvin Tofller descreve com muita clareza as três ondas de desenvolvimento da humanidade: a primeira seria a revolução agrícola; a segunda seria a revolução industrial; já a terceira onda está sendo provocada pelo aparecimento de novas tecnologias. É interessante observar que estas ondas se sobrepōem, no tempo "(A Terceira Onda". Rio de Janeiro. Record. 1985. 11ª Edição).

(2) A informatização da socicdade é termo que já vem sendo utilizado pelos franceses, para designar as modificaçoes que a informática está introduzindo na sociedade. Este termo se tornou difundido graças ao trabalho de Alain Minc e Simon Nora, em seu relatório realizado a pedido do governo francês. ("L'Informatisation de la Société". Paris, La Documentation Française. 1978).

(3) Sc guimos a clara descrição que nos faz. Carlos Alberto Bittar, em artigo recente, publicado na Revista dos Tribunass, n 565, pág. 12. 
mento do processamento, para a obtenção dos resultados procurados, os quais serão, posteriormente, acumulados de modo ordenado pela máquina. Mas, é preciso salientar que, sem os programas, não seria possível ao computador atuar: o programa de computador - software, na terminologia informática - é essencial.

Sem o software, não é possível a informática; daí a importância de lhe conceder um tratamento jurídico adequado, de forma a proporcionar um processo de informatizaçāo linear, eqüitativo às exigências sociais. Todavia, a definição de um regime jurídico de proteção não é possível sem a análise das dificuldades colocadas pelo objeto desta proteção.

\section{SOFTWARE}

A abordagem do software como objeto de proteção jurídica suscita uma outra abordagem inicial. É preciso analisá-lo como um produto técnico, isto é, devemos descrevê-lo, indicando as formas por que se apresenta, as suas partes componentes e seus principais problemas.

\section{a. O que é software}

Vulgarmente, o software é conhecido como sendo o programa de um computador. $\mathrm{Na}$ verdade, ele é muito mais do que isto. Tentativas tem sido feitas para definí-lo, mas nenhuma com muito sucesso. A definição que nos parece mais adequada está nas disposições - tipo sobre a Proteção Software ${ }^{(4)}$. Trata do art. $1^{\circ}$ da definiçāo do software.

Deve-se entender por software os seguintes objetos:

- o programa de computador, que é "o conjunto das instruçōes que, uma vez transferidas a um suporte legível da máquina, faz desenvolver uma funçāo, realizar uma conta ou obter um resultado particular, por meio de uma máquina para a elaboraçāo das informações";

- a descrição do programa, que é "a apresentação completa das operaçōes, em forma verbal, esquemática ou outra qualquer, suficientemente detalhada para determinar o conjunto de instruçōes constitutivas do respectivo programa de computador";

- a documentação auxiliar, que é "qualquer outra documentaçāo diversa do programa de computador e da descrição do programa colocada para facilitar a compreensão ou a aplicação do programa do computador, como, por exemplo, descriçōes de problemas ou instruçōes para o uso dos utentes".

(4) As Disposições - tipo sobre a Proteção do Software, datam de 1978 e foram elaboradas pela Organização Mundial da Propriedade Industrial, em Genchra. 
Assim definido, notamos a existência de dois tipos distintos de software, ou seja, o software de base e o software aplicativo. O software de base, ou de controle, refere-se exclusivamente aos modos de funcionamento dos computadores, como máquinas, e que lhes permite desenvolver, simultaneamente, diversas operações.

Por sua vez, o software aplicativo é aquele que, utilizando informações específicas fornecidas pelo operador, permite ao computador obter, em pouquíssimo tempo, resultados específicos, seja de ordem cognoscitiva (como a elaboração de uma informação) seja de ordem prática (como a sincronização do movimento das diversas partes de uma máquina).

\section{b. Partes componentes}

A definição elaborada pelo O.M.P.I., a par da distinção entre software de base e software aplicativo, nos permite identificar as partes componentes do software.

O software, nada mais é do que uma série de instruções consubstanciadas num suporte técnico. Assim, possui um elemento imaterial, e um elemento material.

O elemento imaterial corresponde ao programa propriamente dito, tal como acima descrito. Todavia, o programa, enquanto tal, só existe na idéia de seu criador e, conseqüentemente, não pode ser utilizado na máquina. Assim, necessário à um elemento material, no qual a idéia se corporifique e possa ser transmitida à máquina. Sem este componente o programa não existe no mundo real.

Porém, é preciso salientar que o componente imaterial tem evolução diversa e independente do material, de forma que um novo programa se utiliza de um suporte já antigo, sem que isto altere em nada sua situação. Por outro lado, nada impede que novos suportes sejam criados e que os programas se utilizem de vários deles.

É desta dicotomia que nasce a discutida controvérsia acerca da natureza do software. Ele é bem material ou imaterial? Entendemos que estes dois componentes são inseparáveis, embora distintos; estão numa relaçāo de dependência recíproca, pois um não faz sentido sem o outro.

\section{c. Principais problemas}

A penetraçāo da tecnologia informática em âmbitos sociais sempre mais vastos, criou uma demanda maciça de software, a qual não encontra articulação 
com oferta do mesmo. Por ser um produto de extrema vulnerabilidade, facilmente reproduzível e ilimitadamente utilizável, o software tem sido objeto constante dos fenômenos de pirataria e plágio. Há quem afirme que, aproximadamente, a metade do faturamento do mercado de software é proveniente de software "roubado" de seu produtor e de seu legítimo titular.

Ao lado das medidas técnicas, é preciso tomar medidas para a proteção jurídica do software. Surgem então diversos problemas de difícil solução.

Ocorre que o software tem uma natureza hibrida (componente material e imaterial); é um produto que só existe se corpodificado num suporte e que faz uso de uma linguagem convencional. Tem uma funçāo complexa, pois em si mesmo não apresenta utilidade; está só surge no momento em que ele é introduzido na máquina, permitindo a realização das operações desejadas. $O$ software existe em função de uma máquina. Decorre, também, desta natureza híbrida, a dificuldade de determinar-se o momento da criação intelectual, bem como o objeto desta mesma criação.

Paralelamente a estes problemas que poderíamos chamar de intrínsecos ao software, há os problemas de ordem extrínseca. A disparidade econômica entre os produtores de software tem papel preponderantes, pois do lado de uma IBM, por exemplo, há o pequeno produtor, o qual trabalha num esquema quase que artesanal. A cópia pirata para estes últimos, na maioria dos casos, significa a falência. Há ainda disparidade entre os próprios programas. Um pequeno programa exige menor conhecimento técnico para ser copiado, enquanto que o grande programa raramente sofre pirataria, mesmo porque o seu mercado consumidor é mais reduzido.

Assim, estas são apenas algumas das dificuldades do estabelecimento de um sistema de proteção jurídica eficaz para o software.

\section{A PROTEÇĀO JURÍDICA DO SOFTWARE}

A proteçäo jurídica do software foi um problema pouco relevante, no início: em parte por razóes objetivas, relativas ao limitado desenvolvimento da indústria de software, desproporcionalmente pequena face à indústria de hardware; em parte por razões subjetivas, visto haver monopólio de fato no setor, os pouquíssimos produtores temiam que qualquer forma de proteção jurídica pudesse frear o seu crescimento ${ }^{(5)}$.

(5) Ao tratar da proteção jurídica do software, Costantino Ciampi levanta estas duas razões para explicar o desinteresse em torno deste problema ("Ol Problema della Protegibilitá del Software nell' Ordinamento Giuridico Italiano e Stranicro", in Informática e Diritto, anno IX, fascicolo terzo, Firenze. Le Mionnicr. 1983. pág. 109). 
Todavia, a informatização da sociedade demonstrou a necessidade de uma regulamentação do software, para o seu próprio desenvolvimento. A pirataria e o plágio crescentes passaram a ser preocupação constante.

Desta forma, foram surgindo leis para a proteção do software. Porém ainda há debate quanto ao tipo de proteção adequado.

\section{a. Etapas seguidas}

A contribuição que os juristas deram, até o presente momento, para um eficaz sistema de tutela do software pode ser articulada e distinguida cronologicamente em três fases: princípios gerais do direito, direitos intelectuais autônomos.

O enquadramento das medidas protetoras no âmbito princípios gerais de direito se dá por meio do recurso à responsabilidade civil, e penal, à concorrência desleal e ao segredo industrial e profissional. Assim foi nos primórdios do desenvolvimento da indústria de informática, quando os juristas achavam que as normas para a proteção do software poderiam ser as mesmas previstas, pela lei, para a tutela dos interesses econômicos do indivíduo e da empresa.

Já em anos mais recentes, a evolução técnica do software mudou o cenário dos interesses econômicos em jogo. Os juristas passaram a classificar o software como um bem pertencente à esfera dos direitos intelectuais. Surge, então, uma divergência: seria o software protegido pelo direito da propriedade industrial ou pelo direito do autor? Encontramos soluções legislativas num e noutro sentido, os quais, dentro de uma comparação, apresentam as seguintes vantagens e desvantagens: o direito da propriedade protege o conteúdo do software contra a reprodução e contra o uso do programa, se indissociável de um objeto material, através de um procedimento especial, sendo que a duração da proteção é curta e com extensão apenas sobre o território nacional; por sua vez o direito de autor protege de maneira direta, apenas a forma do programa contra reprodução, mas não quanto ao uso, não requerendo procedimento especial e com longa duração, náo tendo limitações territoriais.

A proteção pelo direito de propriedade industrial foi a forma escolhida num primeiro momento, mas a Convenção de Mônaco estabeleceu expressamente no art. 52, que não é considerada invenção protegida pelo direito de propriedade industrial o programa de computador enquanto tal, deixando a possibilidade de invocar esta proteção para os processos produtivos que implicam na utilização de um programa eletrônico.

Num segundo momento, orientaram-se os juristas para a proteção oferecida pelo direito de autor, a qual é mais condizente com os interesses em jogo e 
com a natureza do software. Entendem eles que o elenco das obras protegidas, tanto na Convenção de Berna, quanto na de Genebra, é exemplificativo e não taxativo; o software não aparece, apenas por razões históricas. $O$ fato é que esta corrente ganhou força e é hoje predominante.

Todavia, o direito de autor é insuficiente para a proteção do software. Assim, caminhamos, hoje, para um regime específico de proteção legislativa do software. Há propostas de uma disciplina com base no direito de autor, como o recente Projeto de Lei no 6.121/85; e, há propostas para uma regulamentação própria, tal como a elaborada pela Organização Mundial da Propriedade Industrial (na verdade, trata-se de uma fusão das diversas formas de proteção já existentes).

Contudo, devemos salientar que estas três fases de Proteção, longe de serem excludentes, se completam. A proteção eficaz seria a que, incluindo o software dentro dos direitos intelectuais, o fizesse por meio de lei específica e, sem abandonar os demais instrumentos oferecidos pelo direito; naturalmente, tal lei específica é fruto da evolução do tratamento jurídico do tema.

\section{b. Tratamento do tema no exterior}

No exterior houve também uma evolução do tratamento jurídico do tema.

A proteção pelo direito de propriedade industrial não vingou. É o que nos prova a lei francesa $n^{\circ}-742 / 78$, a lei alemã no $1 / 81$, a lei italiana no 338/79 e o Patents Act inglês de 77. Resultantes dos princípios estabelecidos pela Convenção de Mônaco, estas leis declaram expressamente a não patenteabilidade do software. Na jurisprudência está é a posição adotada. A Suprema Corte de Cassação italiana, na sentença $n^{\circ} 3.169$, de 14 de maio de 1981 , afirmou o princípio da patenteabilidade do software, mas trata-se de uma decisão isolada. Por sua vez a Suprema Corte dos Estados Unidos, nos casos de Diamond contra Diehr e de Diamond contra Bradley, respectivamente de março a abril de 1981, chegou a conclusões análogas às da Convenção de Mônaco, colocando fim às discussões sobre se o órgão federal encarregado do registro de patentes deveria ou não negar a patenteação do software (tal órgão já a negava por motivos de ordem prática).

Desta forma, abriu-se caminho para o direito de autor, hoje dominante. Todos os países que seguem as Convenções de Berna e a de Genebra adotaram as suas diretivas para a proteção do software. Nos Estados Unidos a Comission on New Technological Uses of Copyright Works (CONTU) afirmou que o direito do autor é o modo mais conveniente de proteção; o mesmo se deu com o Whitford Report de março de 1977, na Inglaterra. Numerosas decisōes jurisprudenciais estão afirmando esta tese: nos Estados Unidos (Apple Computer contra 
Franklin Computer, agosto de 1983), na França (Tribunal de Comércio de Paris, novembro de 1980, Babolat contra Maillot Witt), na Alemanha (Oberlandsgerichts de Karlsruhe, fevereiro de 1983) e também no Japão (Corte Distrital de Tokio, dezembro de 1982).

Devido à insuficiência da legislação sobre direito de autor, surge a necessidade de uma norma específica. Geralmente, tem-se dado proteção específica dentro do direito de autor, tal como o Computer Software Act de 1980, nos Estados Unidos. Nos países europeus ainda não há legislação específica, mas tão-somente comissões que estudam esta possibilidade, a exemplo da já mencionada Comissão Withford e da Comissão formada dentro da Comunidade Econômica Européia.

\section{c. Tratamento do tema no Brasil}

Por motivos óbvios, o tema só passou a ser discutido entre nós quando já tinha tido uma razoável disciplina no exterior. ${ }^{(6)}$

O Código de Propriedade Industrial exclui expressamente a patenteação do software, na letra h, do art. 9‥ Logo recorreu-se ao direito de autor, assim como o fizeram os países estrangeiros.

A criação da Secretaria Especial da Informática veio dar novo impulso, conduzindo à elaboração de leis especiais, no Brasil. Talvez o projeto mais recente seja o Projeto de Lei no 6.121/85, que prevê a proteção do software com base no direito de autor. Há também projetos com um sistema híbrido de proteção, tal como os projetos elaborados pela Assespro e pela Sucesu.

A discussão do tema já atingiu, até agora, a doutrina e a legislação. O Poder Judiciário ainda não teve oportunidade de se manifestar a respeito. (7)

Resta-nos, ainda, salientar que a proteção do software por uma lei própria não significa a exclusão dos demais mecanismos existentes, ou seja, a concorrência desleal, a responsabilidade civil e o sigilo profissional, dentre outros.

(6) Na verdade a tutela jurídica do software só tomou com as atividades da Secretaria Especial da Informática e sobretudo, após a criação da Política Nacional de Informática (Lei $\left.n^{-7} 7.232 / 84\right)$.

(7) Não temos nenhuma notícia sobre manifestação da jurisprudência acerca deste tema. Fìmos um levantamento da jurisprudência, nos últimos cinco anos, junto à Revista dos Tribunais e à Revista Trimestral de Jurisprudência, porém nada encontramos. Contudo temos conhecimento de uma proposta pela IBM contra a SACCO, fundada em venda de programas copiados. 


\section{O SOFTWARE NO DIREITO DE AUTOR}

Conforme observamos, tanto no exterior, quanto no Brasil, há uma tendência dominante de estender a proteção do direito de autor ao software. Vejamos, então, como isto é possível e em que medida resolve os problemas que acompanham o software.

Primeiramente, é preciso verificar qual é o campo de atuação do direito de autor, e quais os requisitos necessários para a proteção. Num segundo momento devemos avaliar esta proteção, analisando os argumentos contrários e favoráveis. Este caminho nos permite chegar a conclusões sobre a protegilidade do software por este ramo dos direitos intelectuais.

\section{a. Campo de atuaçāo do direito de autor}

"O direito de autor disciplina as relações decorrentes da criação de obra intelectual, pertencente aos domínios literário, artístico e científico e expressa em uma das múltiplas formas possíveis". ${ }^{(8)}$.

É o ramo dos chamados direitos intelectuais, pois nem toda obra intelectual interessa ao direito de autor; a ele só interessam as obras em si dotadas de utilidade intelectual, ou seja, as obras que têm objetivos estéticos, não importando a intenção do autor ou a sua utilização.

Visa o direito de autor a proteção de autor, seja defendendo o direito da paternidade da obra e a integridade desta, seja defendendo o direito aos resultados econômicos decorrentes da utilização.

A enunciação das obras protegidas surgiu com a Convençāo de Berna, e a partir daí passou a ser uma constante nos textos legais por ela influenciados. A Convenção passou por diversas revisōes, sendo o texto em vigor aquele resultante da revisão de Paris, de 24 de Julho de 1971. Assim, todas as produções do domínio literário, científico e artístico, qualquer que seja o modo ou forma de expressão, são protegidas pelo direito de autor (art. $2^{\circ}$ ). Em seguida, há uma enumeração de obras, porém é unânime o entendimento de que esta remuneração é meramente exemplificativa. ${ }^{(9)}$

(8) Sobre o assunto, ver o interessante trabalho de Carlos Alberto Bittar, intitulado " "I)ireito de Autor na Obra Publicitária” (São Paulo. Revista dos Tribunais. 1981 p. 23).

(9) A Convenção de Berna foi homologada, no Brasil, pelo Decreto n: 79.9(0.5/75. 
A Convenção de Genebra também dispōe genericamente sobre o assunto. ${ }^{(10)}$

No Brasil, a lei atual de direito de autor, inspirada pelas diretrizes de Berna, elenca uma série de obras a título de exemplificação (art. 6).

Isto posto, seria então possível estender a proteção do direito de autor ao software? Para responder esta questão devemos verificar se o software atende os requisitos para tal proteçāo.

\section{b. Requisitos para a proteção}

Dois requisitos básicos podem ser levantados: a atividade do criador e a originalidade.

Entende a doutrina que o autor de obra intelectual é o seu criador. $\mathrm{O}$ autor, por meio de atividade intelectual própria, deve dar uma contribuição que acrescente algo novo à realidade existente: a obra deve resultar da atividade do criador. Porém, não basta que a obra seja concebida na mente do autor; ela deve ser corporificada num suporte físico. Contudo, este suporte com ela não se confunde, de forma que não é necessário que ele também seja resultado da criação do autor. Para o direito de autor importa apenas o produto intelectual, sendo irrelevante a forma do suporte.

A atividade do criador deve acrescentar algo novo do mundo exterior. A obra criada deve ser original, isto é, conter elementos que a distingam das outras. Na verdade, todo criador se utiliza do acervo da humanidade, logo, neste sentido, nenhuma obra é inteiramente nova. Assim, a originalidade deve ser entendida restritivamente, ou seja, como uma contribuição nova do autor a este acervo de conhecimentos, de modo a distinguir sua criação das demais.

Com o desenvolvimento da tecnologia surgiu um grande debate acerca das idéias de criação e de originalidade. Ainda hoje discutem-se estas questões. Na verdade, é bastante difícil saber em que medida a atividade do criador se utiliza de processos técnicos inventados por outros, como no caso da música eletrônica, por exemplo: ou então saber se sua contribuição é realmente original. Se formos por uma linha radical, acabaremos por decidir que não há atividade do criador nem originalidade nestas hipóteses. Na realidade, tal solução é falsa. A tecnologia sempre permite novas combinações, o que dá ao criador uma margem para atuar e inovar, dados esses fundamentais ao próprio desenvolvimento

(10) A Convenção Universal de Genebra foi homologada, no Brasil, pelo Decreto $\mathrm{n}^{2}$ $48.458 / 60$. 
da tecnologia. Se isto não fosse verdadeiro, a inserção da fotografia no campo de direito de autor teria sido impossível.

\section{c. Argumentos contrários}

A esta altura, já é possível analisar os argumentos contrários e favoráveis à inserção do software no campo da tutela do direito de autor.

Começaremos pelos argumentos contrários, cuja análise nos abre duas perspectivas: ou demonstra a impossibilidade da proteção pelo direito do autor ou, vem reforçar esta possibilidade. Diversos são os argumentos dos oposicionistas, de modo que nos ateremos apenas aos mais relevantes.

Muitos acham que o software não pode ser comparado a uma obra literária, artística ou científica, porque o objetivo do programa não tem nenhuma destas características. Porém, o software é, fundamentalmente informação, e como tal só pode ser obra do intelecto. Há muito a doutrina e a jurisprudência abandonaram o entendimento de que a obra protegida deve necessariamente ser de caráter estético. Quando exteriorizadas sob forma literária, tais obras têm sido protegidas, a exemplo do conhecimento "Guia Quatro Rodas". O juízo estético é subjetivo, assim importa a criação intelectual. Há hoje quem afirme que os programas de computador possuem características de obra literária, o que não deixa de ser correto; afinal, uma obra literária não precisa ter como suporte necessário a impressao de seu conteúdo em papel. É bastante curioso observar que as importaçōes de software têm sido feitas sob a designação de importaçóes de livros: a maior parte do software que entra no Brasil, chega como se fosse livro.

Outra crítica que se faz é o que o software não se dıstina a uma comunicação entre os homens, porque não é inteligível e nem tem a finalidade de comunicar qualquer coisa. Com efeito, toda obra do engenho para ser protegida deve ter como finalidade a comunicação de algo. O software seria, então, ininteligível porque se vale de códigos e de uma linguagem convencional que nao são destinados à comunicaçāo. O software é produto para ser utilizado em uma máquina. Este argumento carece de fundamento na medida em que toda linguagem é convencional. O que é o idioma português senão uma série de combinações entre símbolos (letras do alfabeto) e os significados (palavras, frases) que lhe são atribuídos? As diferentes linguagens informáticas, tais como o Cobol, a Fortran e a Basic, entre as mais difundidas, são uma linguagem como qualquer outra. Têm a finalidade de comunicar algo para aqueles que a conhecem, da mesma forma que o africano só é compreendido por aqueles que vivem na África do Sul - e, nem por isto deixa de ser linguagem. O software vale-se de uma linguagem inteligível, cuja finalidade é comunicar um saber, pouco importando a natureza deste saber. 
Os oposicionistas apontam que o software não pode ser protegido por the faltar o requisito da materialidade. O software é uma informação, apesar do indispensável suporte físico. $\mathrm{O}$ direito de autor não protege a idéia enquanto tal, mas a partir do momento em que ela se transfere para um corpo mecânico, ela se torna uma obra protegida. Em nosso entender, o mesmo ocorre com o software. Por certo, é impossível tutelar a informação, mas, uma vez inserida num suporte físico (disquete, fita magnética, etc...) não há como lhe negar esta tutela. Frise-se bem que a tutela do conteúdo do suporte físico, não implica na necessária tutela deste. Negar-se a proteção do direito de autor com base neste argumento seria o mesmo que negar proteção à obra musical: a música existe no intelecto, mas se corporifica na partitura.

Entendem alguns oposicionistas que a tutela oferecida pelo direito de autor é insuficiente por duas razões: cobre somente a forma e, não a substância da idéia; veda a reprodução e a comercialização, mas não a utilização. Em relação ao primeiro argumento podemos dizer que a substância da idéia é o algorítmo de solução, porém o algarítmo em si nao apresenta nenhum valor. Os programas de computador são seqüências de comandos para que a corrente elétrica perfaça sucessivamente diversos percursos, para executar as tarefas desejadas. Logo, o que interessa proteger não é o algorítmo de solução, e sim a solução em si, isto é, a forma pela qual os algorítmos são combinados. Deste modo, a tutela invocada é suficiente.

Quanto ao segundo argumento, este também não encontra fundamento. $\mathrm{O}$ autor é titular de direitos morais e patrimoniais sobre a obra que produziu; os direitos patrimoniais abrangem o direito de utilizar, fruir e dispor da obra, tornando dependente da autorização do autơ qualquer forma de sua utilização. $O$ direito de autor veda não apenas a reprodução e a comercialização não autorizadas, bem como qualquer utilização nestas condições. O problema não está na utilização ilícita que não estaria sendo vedada - e sim no controle eféivo, porém esta é uma outra questão. Se fôssemos seguir este caminho, acabaríamos por ter de admitir que o direito de autor não impede a utilização de livros e de música: qualquer pessoa pode ir a uma biblioteca, ler um livro e, a partir daí, desenvolver outras idéias; grande é o número de lojas que utilizam música para atrair seus fregueses e que não pagam nada por esta utilização devido à falta de controle efetivo. Como vemos, o direito de autor protege o software contra toda e qualquer forma de utilização.

Todos sabemos que o segredo é da essência do mercado software. Assim sendo, os oposicionistas veem no registro uma ocasião de evasão de informação. Por certo, tem ocorrido com freqüência no Brasil. Contudo este argumento não resiste à crítica. Trata-se de um problema técnico, que nada tem a ver com a tutela do direito do autor. $O$ registro é necessário e este problema poderia ser facilmente sanado com a criação de um registro próprio. Se admitíssimos a 
validade deste argumento, teríamos que desistir de todo e qualquer registro. A função do registro é essencialmente de publicidade e, neste caso, o autor de um livro que o registrasse antes de editá-lo, faria com que ele perdesse a característica de inédito, o que não é verdade. Logo, o registro não implica na perda do sigilo, sobretudo na medida em que for especialmente concebido para esta finalidade. Por outro lado, a utilização da obra já significa a quebra do sigilo, pois é extremamente fácil copiar o software aplicativo e não de todo impossível copiar o software de base. Portanto, aqueles que invocam o registro como argumento contrário, e fazem sem conhecimento de causa.

Critica-se também a inadequação da tutela do direito de autor em virtude de sua longa duração e dos interesses envolvidos. O software é a chave da sociedade informática; é de interesse social que ele seja um bem público, mesmo porque o pagamento de direitos pode retardar o processo de desenvolvimento do setor e, conseqüentemente, da sociedade como um todo. $O$ enquadramento do software no campo do direito de autor foge às questōes de ordem política, pois qualquer tratamento que lhe seja dado não modifica a substância da relação entre o autor e a obra: o software continua a ser resultado da atividade criativa do autor, que por sua vez continua, conceitualmente, a ser direito de autor. Invocar o longo prazo de duração para o afastamento do direito de autor revela, no mínimo, desconhecimento do assunto. A natureza, o conteúdo do direito de autor não se modifica em razão de um longo ou curto prazo de proteção. Nada impede que a tutela do direito de autor seja exercida por um pequeno prazo, inclusive porque os direitos morais subsistem a qualquer prazo. Por outro lado, rejeitar o direito de autor com fundamento no interesse público seria no mínimo uma injustiça. $O$ software é extremamente dispendioso e exige um grande esforço, de modo que, se não for protegido, trará prejuízo direto para o criador, e indireto para a sociedade, pois seria um desestímulo à atividade criadora. A proteção do software pelo direito autoral atende aos interesses sociais e propicia um desenvolvimento eqüitativo ao setor de informática.

Entre os argumentos que os oposicionistas sustentam, talvez o mais interessante seja o relativo à originalidade. Segundo eles, o software se utiliza de outros softwares, de uma linguagem convencional e de esquemas lógicos anteriormente já existentes. A atividade do criador não é original. Ora, isto é grande falácia. Toda atividade criadora pressupõe um acúmulo de informaçōes anteriores que a possibilitaram; negar isto seria o mesmo que afirmar: nenhuma criação é original. Assim como um pintor se utiliza do acervo da humanidade, o criador de um software também dele se vale, mas ninguém diria que o quadro do pintor não é original. Então, por que dizer que o software criado nas mesmas condições não é original? O software é um produto novo. A sua novidade intrínseca (originalidade) e extrínseca (jamais conhecida antes) são de difícil avaliação para o leigo em matéria de informática. $O$ autor deve dar uma contribuição que acrescente algo novo à realidade existente, de modo que ao 
direito de autor interessa a novidade intrínseca apenas. Basta que o bem, em si, seja novo, original, sendo irrelevante o fato de ser totalmente desconhecido. É impossível negar a originalidade do software. Portanto, este argumento não tem bases sólidas.

Após a análise de algumas das críticas que se faz à inserção do software no direito de autor, podemos concluir que, longe de demonstrar a impossibilidade desta proteção, os oposicionistas só vêm reforçá-la. Seus argumentos não resistem às críticas e, conseqüentemente, só comprovam a verdade de quem as faz.

\section{d. Argumentos favoráveis}

Vejamos, agora, quais são os argumentos que corroboram para a tutela de software pelo direito de autor. Basicamente, estes argumentos são inferidos das críticas a esta tutela, ou seja, dos argumentos contrários extraímos argumentos favoráveis e, não obstáculos.

O software é uma obra do intelecto, qualquer que seja a significação que lhes seja dada. Provém da idéia de seu criador; ainda que não equiparada, segundo alguns, a uma obra científica, literária ou artística, o software resulta da atividade criadora, a qual é eminentemente intelectual. Pode ocorrer, como vimos, que um programa, não seja inteiramente novo, porém o autor sempre terá um mínimo de atuação. Assim, o criador pode se valer da descrição e da documentação auxiliar de um outro programa para colocar em funcionamento o seu programa, de modo que uma parte do software será sempre fruto de atividade criadora, mesmo porque a simples reorganização que permita novos usos já implica em criatividade.

Estreitamente ligada à criação está a característica de originalidade. Retomando o mesmo exemplo, vemos que uma parte do software será sempre original, toda vez que acrescentar algo novo do mundo real. Não é preciso que o software seja revolucionário para poder receber a tutela do direito de autor. Se fosse assim, pouquíssimas obras poderiam estar sob esta tutela. Por certo, pode ocorrer que o software não tenha nada de original. Neste caso, não será protegido pelo direito de autor, da mesma forma que não o serão todas as obras que não forem originais.

Como o direito de autor não protege toda e qualquer criação intelectual dotada de originalidade, recorre-se ao senso do estético. Porém esta característica já foi declinada de sua essencialidade. E, no caso do software provavelmente ela é de difícil percepção. Contudo, o software tem utilidade intelectual e não material. Daí a sua inserçao no campo do direito do autor. 
Prova de sua utilidade intelectual é o software destinar-se à comunicação entre os homens, ainda que tal comunicação se destine à transmissão de um saber técnico. Achamos difícil ver num manual de engenharia eletrônica, por exemplo, um caráter estético, porém este manual tem uma finalidade intelectual, que é a transmissão de um saber técnico, que por sua vez é incompreensível para o leigo no assunto. $O$ mesmo se passa com o software, e não há como negar o fato tão evidente.

O software atende os requisitos do direito de autor: há atividade do criador e há originalidade. Entretanto, reconhecemos algumas dificuldades técnicas que daí resultam, tais como o longo prazo e o sigilo no registro. Em termos conceituais não há como fugir a esta tutela. As pequenas dificuldades podem ser facilmente sanadas através de uma legislação ad hoc, que poderia, entre outras coisas, disciplinar as novas formas de utilização, não previstas na lei de direitos autorais, a exemplo do pagamento de direitos pela consulta por computador a um outro computador. A tutela atual, numa primeira fase, já solucionaria a situação caótica em que se encontram os produtos de software; num segundo momento, pode ser aprimorada a atender a todas as necessidades.

Devemos, também salientar que a auséncia de procedimentos complicados para o registro propiciam a tutela pelo direito de autor, pois atua como um incentivo para esta modalidade de proteção. Num mercado onde a rapidez da atividade criadora é essencial, nāo faz sentido perder o tempo ganho na criação com questôes burocráticas. Todavia, reafirmamos a necessidade do registro, no sentido de que a certeza e a segurança por ele oferecidas, só viria colaborar para o desenvolvimento do setor de informática, e não prejudicá-lo.

Um outro argumento favorável, já mencionado anteriormente, é a enumeração exemplificada das obras protegidas. Se esta fosse taxativa, a inserção do software no rol das obras protegidas seria legalmente impossível e talvez, fosse até necessária a revisão da legislação. Este é um dado que impulsiona, favoravelmente, o software para o direito de autor.

Muitos outros argumentos favoráveis poderiam ser levantados, mas em nosso entender não se trata de pesar prós e contras e de decidir-se pelo que tiver maior número. Em verdade, a escolha do tipo de proteção decorre da natureza, da essência do bem a ser protegido. O software é em sua essência um bem intelectual dotado de originalidade; a relação que o prende ao seu criador é nitidamente de direito de autor. Logo, o argumento que invocamos já é suficiente para justificar a tutela do software pelo direito de autor. Não há como escapar desta realidade. Este é o único argumento básico e genuíno, pois no mundo, como já dizia Shakespeare, ser ou não ser é a questão; de modo que forçar o enquadramento do software numa outra categoria de bens e de relaçōes jurídicas, é forçar o não ser a ser, o que é impossível. 
A proteção jurídica do software só pode ter como fundamento o direito de autor.

\section{LEGISLAÇĀO ESPECIAL}

Após uma breve análise dos principais problemas que envolvem o software e, do seu posicionamento face ao direito de autor, podemos chegar a uma única conclusão: o software devè ser disciplinado pelo direito, mas em lei especial, de modo a atender suas particularidades. Note-se bem que não estamos propondo uma legislação sui generis, a meio caminho entre o direito de autor e o direito de propriedade industrial. Propomos sim, uma legislação especial no sentido de ser específica para o software, sem o afastamento do direito de autor.

\section{a. Base no direito de autor}

Conforme tivemos oportunidade de observar, o software apresenta certas particularidades que tornam difícil a operacionalização da lei de direitos autorais. Contudo, isto não modifica sua natureza, daí a sua regulamentaçāo seguir os conceitos de direito de autor.

Em lei especial, a relaçāo jurídica entre o software e seu autor deve ser de direito autoral. Conseqüentemente, todos os princípios e conceitos devem também ser de direito autoral. Parece-nos que esta é a tendência dominante entre os criadores de software e a doutrina jurídica. Seguindo esta orientação, há um projeto no Congresso Nacional - Projeto de Lei no 6.121/85 - de autoria do Deputado Francisco Amaral, no sentido de estender as disposições da lei de direitos autorais ao software.

Um regime específico pode ser assegurado com modificações das normas que disciplinam o direito de autor, no plano nacional, ou com protocolos anexos às Convenções de Berna e de Genebra, no plano internacional. Porém, mais adequado nos parece introduzir uma legislação específica no sistema vigente e celebrar um novo tratado ou um nova convenção que discipline autonomamente o software. Aqui, vale entāo retornar os exemplos dos Estados Unidos, que contam com um Computer Software Copyright Act de 1980 e com um Copyright Act de $1976^{(11)}$.

\section{b. Atençāo aos principais problemas}

A legislação especial deve atender às características particularíssimas do software sobretudo no que diz respeito ao tempo e à extensão da proteção, ao

(11) A lei brasileira sobre direito de autor em vigor, é a Lei n 5.988/73. 
registro e ao sigilo, à disparidade entre os tipos de software, e à especial posição do criador empregado.

Quanto à duração da proteção, parece ser adequado um prazo entre cinco e vinte anos, segundo a complexidade do programa e os custos nele envolvidos. Isto propiciaria ao autor usufruir de sua obra e à sociedade aproveitar-se de sua criação para o seu desenvolvimento.

A extensão territorial desta tutela deve necessariamente ser assegurada num plano internacional. Uma proteção territorialmente limitada seria desastrosa. Hoje, é possível transferir um programa de um país para outro, ou então usar por computador um programa estrangeiro. Haveria daí, a criação de verdadeiros paraísos informáticos, com graves prejuízos para a comunidade internacional.

Apesar de muito criticados, somos favoráveis à instituição de um sistema próprio de registro para o software. O sigilo no mercado de software é muito importante - é mesmo regra constante, de modo que é muito difícil que o nome do criador se torne público, sobretudo quando o software é industrializado e comercializado por outrém. O registro oferece segurança e certeza ao autor do software e não implica na necessária publicidade do conteúdo do programa, basta que seja criado um procedimento especial de registro. Sem o registro, será muito difícil o controle do software.

Por outro lado, não nos parece razoável proteger-se o software de base do mesmo modo que o software aplicativo. A gama de interesses envolvidos num e noutro são diferentes, seja em relação ao custo envolvido na criação, seja em relação às modalidades e à freqüência de utilização, seja ainda em relação aos interesses sociais envolvidos (a importância de que desfrutam é diferente). Logo, uma lei específica deve estar atenta a esta questão, disciplinando, individualmente, cada tipo de software. Paralelamente, deve-se fazer atenção à diferença que existe entre o programa, a sua descriçāo e a sua documentação auxiliar, pois o software é a unidade destes três dados, mas cada um deles é independentemente dos demais.

A posição do empregado criador de software deve ser igualmente disciplinada pela lei especial. A pessoa contratada para criar software deve contar com uma proteção ampla contra os abusos que normalmente ocorrer. Por certo o empresário tem o título sobre a obra, e conseqüentemente, sobre os direitos patrimoniais respectivos. Contudo esta solução não nos parece justa. Ao criador deveria ser pago, no mínimo, um percentual sobre a utilização da obra, já que grande é o esforço envolvido e relevante é sua contribuição para a sociedade.

Para a operacionalização desta tutela seria bastante interessante a criação de um órgão específico, o qual teria como finalidade, entre outras, realizar o 
registro do software, fiscalizar o efetivo cumprimento das disposições legais e arrecadar e distribuir os direitos autorais. Poder-se-ia, inclusive, conceder-lhe competência para solucionar questões relativas ao software, já que o processo administrativo é sempre mais célebre e sigiloso do que o processo judiciário.

Em relação ao processo judiciário, a lei especial poderia criar um procedimento especial que atendesse às exigências de rapidez e de segredo do mercado de software. Uma demanda judicial pode ser desastrosa para a imagem de uma empresa, sem falar nos prejuízos que seriam causados pela revelação do segredo do software e pela demora da decisão. Se pelas peculiaridades características do usucapião criou-se um procedimento especial, por que não fazer o mesmo para o software?

Um outro ponto que a lei deve explicitar muito bem refere-se aos objetivos da proteção. Não basta vetar a cópia para fins comerciais, deve-se também impedir a tradução do programa de uma linguagem para outra, a utilização do conteúdo da informação em outro programa, o remanejamento, a modificação ou a inserção em outro programa e a utilização fora dos casos autorizados, entre uma série de outros pontos relevantes. Contudo, tais objetivos não devem ser descritos de forma taxativa, pois isto produziria o envelhecimento precoce da lei.

Temos, ainda duas observações a fazer. A criação de uma lei especial não significa, de forma alguma, a exclusão de outras medidas protetoras previstas pela legislação, em geral, tal como a responsabilidade civil e a violação no segredo industrial.

Finalmente, devemos chamar a atenção para o fato de ser necessária a colaboração entre o jurista e o informático. Sem este intercâmbio de perspectivas jamais chegaremos a produzir uma legislação eficaz e plástica, capaz de atender às exigências presente e futuras do setor de informática e da própria sociedade.

A questão da informática é essencialmente política ${ }^{(12)}$. Assim não é impossível que vejamos amanhã o software sendo tutelado por normas totalmente novas. Contudo, a solução juridicamente correta é a proteção do software pelo direito de autor. $\mathrm{O}$ recurso a um outro tipo qualquer de solução significa a institucionalização do software pirata.

(12) Por ser extremamente importante para todos os segmentos sociais, a informática tornou-se uma questāo política. Este é um ponto tão sensível, que chegamos a ver os partidos políticos de esquerda se unirem aos de direita, viabilizando a aprovação da reserva de mercado e ainda, a criação de novos requisitos para a definição da nacionalidade das empresas de informática (Lei n-7.232/81). 


\section{BIBLIOGRAFIA}

BITTAR, Carlos Alberto - "Direitos Autorais nas Criaçōes Publicitárias", in Revista de Informação Legislativa no 83, págs. 427:440. Brasília. Subsecretaria de Edições Técnicas do Senado. Federal. 1984.

BITTAR, Carlos Alberto - "Computaçăo e Direito", in Revista dos Tribunais no 565, págs. 9:20. São Paulo. Revista dos Tribunais. 1982.

BITTAR, Carlos Alberto - "Direito de Autor na Obra Publicitária". São Paulo, Revista dos Tribunais. 1981.

BITTAR, Carlos Alberto - "Direito de Autor na Obra Feita sob Encomenda". Sāo Paulo. Revista dos Tribunais. 1977.

CIAMPI, Costantino - "Il Problema della Protegibilitàdel Software e Diritto, anno IX, fascicolo terzo, págs. 109:140. Firenze. Le Monnier. 1983.

CORONA, Eduardo Galán - "En torno a la Proteción Juridica del Soporte Lógico", in Informática e Diritto, anno IX, fascicolo terzo, págs. 109:140. Firenze. Le Monnier. 1983.

FROSINI, Vittorio - "Il Diritto nella Società Tecnológica”. Milano. Giuffré. 1981.

GIANNANTONIO, Ettore - "Introduzione All'Informatica Giuridica”. Milano. Giuffrè. 1984.

GOMES, Orlando et al. - "A Proteção Jurídica do Software”. Rio de Janeiro. Forense. 1985.

LEITE, Julio César do Prado - "Proteçāo legal para o Software", in Revista de Informação Legislativa n 83, págs. 441:450. Brasília. Subsecretaria de Ediçōes Técnicas do Senado Federal. 1984.

MANSO, Eduardo Vieira - "A Informática e os Direitos Intelectuais". São Paulo. Revista dos Tribunais. 1985.

NORA, Simon \& MINC, Alain - "L'Informatisation de la Sociétè". Paris. Da Documentation Française. 1978.

SIMITIS, Spiros et al. - “Kommentar zum Bundesdatenschutzgesetz". Baden Baden. Nomos. 1981. 3. Auflage.

SOARES, José Carlos Tinoco - "Proteção para os Programas de Computadores", in Revista de Direito Mercantil no 17, págs. 39:44. São Paulo. Revista dos Tribunais. 1975.

TOFFLER, Alvin - “A Terceira Onda”. Rio de Janeiro. Record. 1985. 11 a Edição.

UBERTAZZI, Luigi Carlo - "Raccolte Eletroniche di Dati e Diritto d'Autore: Prime Riflessioni”, in La Tutela Giuridica del Software - Diritto dell'Informática 2, Collana diretta da Guido Alpa. Milano. Giuffrè. 1984. 
VERKADE, D. W. F. - "Legal Protection of Computer Programs: Towards the Copyright Approach", in Annuaire de l'A.A.A., volume 45/46, págs. 75:83. La Haye. A.A.A. $1975 / 76$. 